\title{
AS DIMENSÕES SOCIAIS DA CIÊNCIA E DA TECNOLOGIA EM LIVROS DIDÁTICOS INTEGRADOS DE CIÊNCIAS DO $4^{\circ}$ ANO DO ENSINO FUNDAMENTAL
}

\author{
JULIANA PINTO VIECHENESKI ${ }^{*}$ \\ https://orcid.org/0000-0002-2918-2640 \\ ROSEMARI MONTEIRO CASTILHO FOGGIATTO SILVEIRA"** \\ https://orcid.org/0000-0002-0432-5182 \\ MARCIA REGINA CARLETTO ${ }^{11}{ }^{* * *}$ \\ https://orcid.org/0000-0003-3442-5093
}

RESUMO: Este artigo apresenta os resultados de um estudo que analisou as abordagens relativas às dimensões sociais da ciência e da tecnologia em livros didáticos integrados de ciências humanas e da natureza do $4^{\circ}$ ano do Ensino Fundamental. A perspectiva metodológica foi de natureza qualitativa e optou-se pelo uso de técnicas de análise de conteúdo com base em Bardin (2011). Os resultados indicaram que as relações ciência-tecnologia-sociedade (CTS) recebem espaço pouco expressivo nos livros didáticos e sua abordagem reflete uma visão de ciência e tecnologia socialmente neutras. Sugere-se a incorporação crítica das inter-relações CTS nos livros didáticos e reitera-se a necessidade de formação docente continuada, nas quais sejam privilegiadas a reflexão, o diálogo e o apoio de professores formadores na concretização de um ensino mais crítico quanto às dimensões sociais do desenvolvimento científico-tecnológico.

Palavras-chave: Livro Didático. Ensino de Ciências. Anos iniciais do Ensino Fundamental. Ciência-TecnologiaSociedade.

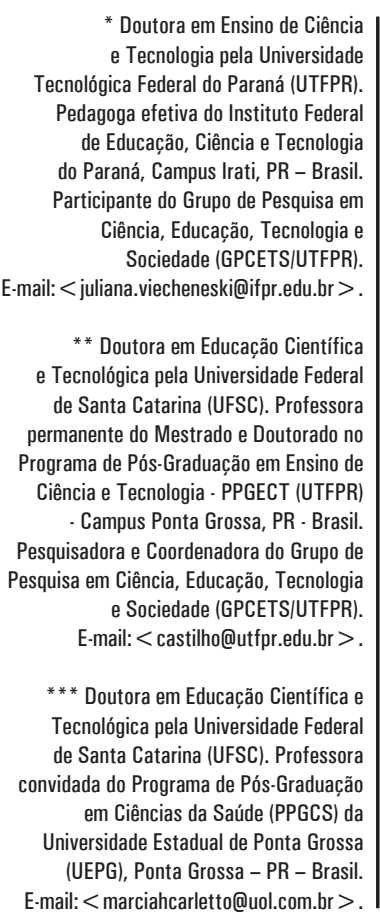

* Doutora em Ensino de Ciência e Tecnologia pela Universidade ecnológica Federal do Paraná (UTFPR). Pedagoga efetiva do Instituto Federa de Educação, Ciência e Tecnologia do Paraná, Campus Irati, PR - Brasil. ricipante do Grupo de Pesquisa em Ciência, Educação, Tecnologia e Sociedade (GPCETS/UTFPR) E-mail:<juliana.viecheneski@ifpr.edu.br >

* * Doutora em Educação Científica e Tecnológica pela Universidade Federal de Santa Catarina (UFSC). Professora permanente do Mestrado e Doutorado no rograma de Pós-Graduação em Ensino de Ciência e Tecnologia - PPGECT (UTFPR)

- Campus Ponta Grossa, PR - Brasil.

Pesquisadora e Coordenadora do Grupo de Pesquisa em Ciência, Educação, Tecnologia e Sociedade (GPCETS/UTFPR) E-mail: < castilho@utfpr.edu.br >

** Doutora em Educação Científica e Tecnológica pela Universidade Federa de Santa Catarina (UFSC). Professora do Programa de Pós-Graduação (D) (UEPG), Ponta Grossa - PR - Brasil.

E-mail:<marciahcarletto@uol.com.br >.

\footnotetext{
' Instituto Federal de Educação, Ciência e Tecnologia do Paraná, Irati, PR - Brasil.

" Universidade Tecnológica Federal do Paraná, Programa de Pós-Graduação em Ensino de Ciência e Tecnologia, Ponta Grossa, PR - Brasil.

III Universidade Estadual de Ponta Grossa, Programa de Pós-Graduação em Ciências da Saúde, Ponta Grossa, PR - Brasil.
} 
THE SOCIAL DIMENSIONS OF SCIENCE AND TECHNOLOGY IN INTEGRATED TEXTBOOKS OF THE SCIENCE OF THE 4TH GRADE OF ELEMENTARY SCHOOL

ABSTRACT: This article presents the results of a study that analyzed, focusing on interrelationships, the social dimensions of science and technology in integrated textbooks of the humanities and nature sciences of the $4^{\text {th }}$ grade of Elementary School. The methodological approach was qualitative in nature and we opted for the use of content analysis techniques based on Bardin (2011). The results indicated that the STS relations receive an inexpressive space in textbooks and their approach reflects a vision of socially neutral science and technology. It is suggested the critical incorporation of the STS interrelationships in didactic manuals and reiterates the need for continuing teacher training, in which the reflection, the dialogue and support of teachers educators are favored in the achievement of a more critical teaching regarding the social dimensions of scientific and technological development. Keywords: Textbooks. Science teaching. Early years of Elementary School. Science-Technology-Society.

\section{LAS DIMENSIONES SOCIALES DE LA CIENCIA Y LA TECNOLOGÍA EN LIBROS DE TEXTO INTEGRADOS DE CIENCIAS DEL CUARTO AÑO DE LA EDUCACIÓN PRIMARIA}

RESUMEN: Este artículo presenta los resultados de un estudio que analizó los enfoques relacionados con las dimensiones sociales de la ciencia y la tecnología en los libros de texto integrados sobre ciencias humanas y naturaleza en el cuarto año de la educación primaria. La perspectiva metodológica era de carácter cualitativo y optamos por el uso de técnicas de análisis de contenido basadas en Bardin (2011). Los resultados indicaron que las relaciones ciencia-tecnología-sociedad (CTS) reciben poco espacio en los libros de texto y su enfoque refleja una visión socialmente neutral de la ciencia y la tecnología. Se sugiere la incorporación crítica de las interrelaciones de CTS en los libros de texto y se reitera la necesidad de continuar la formación del profesorado, en las cuales la reflexión, el diálogo y el apoyo de los formadores de docentes sean privilegiados en la realización de una enseñanza más crítica en términos de dimensiones sociales del desarrollo científico-tecnológico.

Palabras clave: Libro de texto. Enseñanza de las ciencias. Primeros años de primaria. Ciencia-Tecnología-Sociedad. 


\section{INTRODUÇÃO}

Construir uma visão crítica de ciência e de tecnologia como processos humanos, históricos e socialmente constituídos, implica um processo de desconstrução de uma concepção tradicional e essencialista que permaneceu (e ainda permanece) presente em diversos campos de atuação social, tais como da pesquisa, das políticas públicas, da educação, entre outros.

No meio educacional, as concepções que os professores possuem acerca da ciência, da tecnologia e de suas inter-relações com a sociedade, assim como as suas concepções sobre a educação de modo geral, e sobre o ensino de ciências, em particular, influenciam diretamente as práticas pedagógicas, de modo a favorecer ou limitar os processos de ensino e aprendizagem, conforme apontam vários pesquisadores (CARLETTO, 2009; MEGID NETO; ROCHA, 2010; MONTEIRO; TEIXEIRA, 2004; PRAIA, CACHAPUZ; GIL-PÉREZ, 2002).

Tais concepções são construídas socialmente, alicerçadas em experiências pessoais, culturais e profissionais; processos formativos iniciais e continuados; orientações oficiais; referenciais teórico-metodológicos e materiais didáticos disponibilizados nas escolas, entre outros fatores, que constituem referências tanto para os pressupostos teóricos e metodológicos assumidos no exercício da docência, quanto para as decisões acerca das temáticas a serem abordadas em sala de aula, a ênfase e o enfoque a ser dado a cada uma delas (MEGID NETO; ROCHA, 2010; MONTEIRO; TEIXEIRA, 2004; SACRISTÁN, 2000).

Nesse contexto, destaca-se que embora os livros didáticos não se constituam como únicos instrumentos do trabalho docente (NASCIMENTO, 2002), eles têm espaço garantido nas escolas da educação básica, mediante o Programa Nacional do Livro e do Material Didático (PNLD), e desempenham um importante papel para muitos professores que o utilizam como subsídio em suas práticas educativas e em sua própria formação (FERNANDEZ; SILVA, 2008; PINHÃO; MARTINS, 2013). Vale lembrar que como produtos culturais, os livros didáticos divulgam não apenas conteúdos, mas maneiras de compreender a natureza da atividade científica e o processo de ensinar e aprender ciências (MARTINS, 2012). Sendo assim, em conjunto com outros fatores, podem reforçar ou alterar práticas pedagógicas e compreensões sobre a ciência e seu ensino (CARNEIRO; SANTOS; MÓL, 2005; MARTINS, 2012; MEGID NETO; FRACALANZA, 2006).

Diante do exposto, a problemática levantada foi a seguinte: quais abordagens os livros didáticos integrados de ciências, destinados ao $4^{\circ}$ ano do Ensino Fundamental, apresentam no que se refere às relações entre ciênciatecnologia-sociedade? Para respondê-la, analisaram-se os livros didáticos integrados de ciências humanas e da natureza, do $4^{\circ}$ ano do Ensino Fundamental, correspondentes ao triênio 2016-2018 do PNLD.

\section{O ENFOQUE CTS NA EDUCAC̣ÃO EM CIÊNCIAS}

Em consonância com Santos (2008, 2012) e Auler (2002, 2011), entendese que o ensino de ciências com enfoque CTS, em uma perspectiva crítica de formação para a cidadania, implica uma compreensão ampliada a respeito da não 
neutralidade da ciência e da tecnologia, o que pressupõe um exercício contínuo de problematização e de desvelamento da ampla rede de valores e interesses sociais, políticos e econômicos que permeiam a atividade científico-tecnológica. Requer reconhecer que esses valores são incorporados e materializados nos resultados/ produtos científico-tecnológicos e que nem sempre eles estão em sintonia àqueles ligados aos princípios humanos, éticos e socioambientais, mas refletem os anseios e os princípios de certos grupos/atores sociais, cuja preocupação central, não raras vezes, é a maximização dos seus lucros em detrimento das necessidades coletivas. Importa, também, reconhecer e avaliar com os estudantes os benefícios, os riscos e as repercussões negativas que o desenvolvimento científico-tecnológico pode gerar (AULER, 2011; BAZZO; PEREIRA; BAZZO, 2014; CACHAPUZ, 2011; SANTOS, 2007; STRIEDER, 2012).

Defende-se, desse modo, a promoção de práticas educativas nas quais indagações em torno do porquê, como, em qual contexto sociocultural e histórico, a favor de que e de quem se faz ciência e tecnologia, quais controvérsias estão envolvidas e quais valores balizam a produção científico-tecnológica, permeiem todo o processo de ensino e aprendizagem (PINHEIRO; SILVEIRA; BAZZO, 2009; ROSA; AULER, 2016). Esse tipo de formação traz como prerrogativa o desenvolvimento de uma compreensão abrangente da realidade, um senso de coletividade, posicionamento crítico e um engajamento ativo na luta em favor do bem e das necessidades coletivas (HODSON, 2014).

Nessa perspectiva, a educação em ciências vai ao encontro dos pressupostos freireanos. Reconhece-se a necessidade do resgate da "vocação ontológica" dos sujeitos que é humanizar-se. Ou seja, reconhece-se tal como Freire (2003), que é preciso resgatar a vocação de ser sujeito, de ser agente de transformação $\mathrm{da}$ realidade. $\mathrm{E}$ isso implica conceber os sujeitos como "[...] seres inacabados, inconclusos, em e com uma realidade que, sendo histórica também, é igualmente inacabada" (FREIRE, 2003, p. 72, destaque do autor).

A busca pela humanização não ocorre sem o reconhecimento de que somos inacabados e de que a realidade que nos cerca está em constante construção, não é algo predeterminado, mas constitui-se como campo de possibilidades. $\mathrm{O}$ mundo é uma construção histórico-cultural, no qual há possibilidades de opção, de alteração do cenário societário atual e os indivíduos, como "sujeitos e não objetos" se tornam "[...] capazes de comparar, de valorar, de intervir, de escolher, de decidir, de romper" e por isso se fazem "seres éticos" (FREIRE, 2002, p. 36).

Segundo Freire (2002, p. 37), é impossível pensar o ser humano fora da ética, isso seria uma transgressão. Para ele:

[...] transformar a experiência educativa em puro treinamento técnico é amesquinhar o que há de fundamentalmente humano no exercício educativo: o seu caráter formador. Se se respeita a natureza do ser humano, o ensino dos conteúdos não pode dar-se alheio à formação moral do educando.

Isso significa que o processo educativo não pode ser realizado à margem de uma formação ética, se o desejado é a construção de uma compreensão crítica da realidade e o comprometimento dos sujeitos para com as questões e necessidades coletivas. 
De acordo com Freire (2003), a maneira de contribuir para que o sujeito possa se inserir na construção e na transformação do seu próprio entorno social, é superar uma compreensão ingênua da realidade por uma crítica, o que não se faz sem a problematização do meio social, das suas contradições, sem o diálogo, a reflexão e a superação da "cultura do silêncio".

A "cultura do silêncio" é "[...] típica das estruturas fechadas como a do latifúndio" e é "[...] gerada nas condições objetivas de uma realidade opressora"; é assinalada por uma percepção fatalista da realidade, pela ausência da participação social em processos decisórios, pela alienação e passividade (FREIRE, 2006, p. 37).

Superá-la requer processos educativos com abordagem problematizadora, reflexiva, dialógica, interdisciplinar, contextualizada e democrática, tal como proposto pela educação em ciências com enfoque CTS, na perspectiva da formação para a cidadania. As práticas educativas com esse enfoque envolvem propostas mais abertas ao entorno social, aos temas/problemas contemporâneos que afligem a sociedade e que despertam a curiosidade, o questionamento, o envolvimento emocional e efetivo dos estudantes. Os temas/problemas configuram ponto de partida para a busca de conhecimentos (em diversas áreas) necessários para compreendê-los, para formular um posicionamento crítico, assim como para tomar decisões e intervir socialmente em sua solução (AULER, 2007; SANTOS, 2007).

De um currículo convencionalmente centrado na transmissão de conteúdos, passa-se a atuar em um processo centrado nos alunos e nos problemas reais emergentes que os afetam pessoal e socialmente, em temáticas como alimentação, saúde, saneamento, recursos hídricos, energéticos e minerais, comunicação, transportes, entre outras socialmente importantes, a partir das quais é possível abordar os sujeitos, a ciência e a tecnologia, em suas múltiplas relações com a realidade. Nessa perspectiva, a prática educativa é intencionalmente direcionada para contribuir na construção de uma concepção crítica da realidade e uma participação social ativa, no sentido da construção de uma "cultura de participação", conforme sinalizam os trabalhos de Auler (2002, 2007, 2011), Santos (2007a, 2008, 2012) e Strieder (2012).

Mas o que vem a ser essa "cultura de participação"? Por "cultura de participação" entende-se a participação dos sujeitos em processos decisórios relacionados à ciência e à tecnologia, em um processo de democratização dessas decisões. Sendo assim, além de auxiliar o sujeito a reconhecer e compreender as problemáticas do cotidiano, o trabalho educativo com enfoque CTS assume o propósito de contribuir para o desenvolvimento de cidadãos com uma postura crítica e ativa, de comprometimento com a busca e construção de caminhos alternativos para os problemas reais do entorno social, relacionados à ciência e à tecnologia, o que implica uma compreensão crítica das inter-relações CTS (STRIEDER, 2012).

Para tanto, desvelam-se os mitos pautados na suposta neutralidade da ciência e da tecnologia, quais sejam: a pretensa superioridade/neutralidade do modelo de decisões tecnocráticas, a perspectiva salvacionista da ciência e da tecnologia e o determinismo tecnológico, discutidos por Auler (2002, 2011).

Entre os pesquisadores que têm se dedicado a aprofundar o conceito de participação social, em sintonia com a realidade e as necessidades do contexto brasileiro, pode-se destacar: Auler (2011), Rosa e Auler (2016), Santos, R. (2012), 
Santos e Auler (2015), Santos (2016), Strieder (2012), Strieder e Kawamura (2014). Eles têm resgatado a produção do Pensamento Latino Americano em CTS (PLACTS) no campo educacional e evidenciado a necessidade de problematização dos mitos relativos à ciência e à tecnologia.

Em linhas gerais, esses pesquisadores têm problematizado as limitações de uma perspectiva de participação social reduzida à avaliação das repercussões pósprodução da ciência e da tecnologia. Um discurso comum dessa perspectiva reside em avaliar impactos positivos e negativos da ciência e da tecnologia, no contexto social e natural, enfatizando os benefícios e buscando atenuar as consequências negativas (ROSA; AULER, 2016; SANTOS, 2016).

Auler (2011, p. 86) afirma que "fazer uma avaliação apenas dos impactos pós-produção significa manter intocável, fora do alcance de uma análise crítica, o pano de fundo. Significa abster-se do essencial, focalizando o periférico". Ou seja, a avaliação a posteriori deixa de lado um aspecto essencial, ou melhor, estrutural, que é a crítica aos processos. Para potencializar uma cultura de participação mais ampla e crítica, em processos decisórios relacionados à ciência e à tecnologia, faz-se necessário um trabalho educativo voltado à problematização conjuntural e sóciohistórica do entorno social contemporâneo e do modelo de desenvolvimento científico-tecnológico atual, desvelando os seus valores, os quais muitas vezes, revelam-se consumistas, individualistas, insustentáveis e tecnocráticos.

Isso não quer dizer que uma perspectiva de participação a posteriori não deva acontecer. Muito pelo contrário, esse tipo de participação contribui para questionamentos importantes relacionados à ciência e à tecnologia (ROSA, AULER, 2016; STRIEDER; KAWAMURA, 2014). Todavia há um reconhecimento de que ela é limitada, e de que é necessário avançar para compreensões mais críticas (STRIEDER; KAWAMURA, 2014).

De acordo com Dagnino (2010), se apenas a dimensão do uso da ciência e da tecnologia for colocada em questão, os seus processos de desenvolvimento, que incorporam valores capitalistas, ficam silenciados, ausentes de uma necessária problematização e reflexão crítica. A não consideração de que o direcionamento da atividade científico-tecnológica atende aos valores e aos interesses particulares de determinados atores/grupos sociais, focalizando-se apenas o "bom" e "mau" uso das inovações tecnocientíficas, sinaliza uma visão neutra, instrumental da tecnociência, que poderia servir, indistintamente, a qualquer propósito ou projeto de sociedade.

Em termos das práticas educativas CTS, é necessária a promoção de atividades que integrem juízos de valor, questões éticas e humanas e razão científica, de maneira a instigar os estudantes à investigação, à interação dialógica e à reflexão crítica sobre a ciência, a tecnologia e suas múltiplas dimensões sociais. Envolve questionar não somente os impactos dos produtos finais, mas as agendas de pesquisa, mostrando a importância da participação pública nos processos decisórios, assim como exemplificando e vivenciando experiências de participação, tanto no âmbito individual, quanto no coletivo, conforme ressalta Hodson (2014) e Marques e Reis (2017). 


\section{OS LIVROS DIDÁTICOS DE CIÊNCIAS E O ENFOQUE CTS}

Apesar da crescente diversidade de recursos hoje disponíveis, sobretudo os provenientes da tecnologia da informação e comunicação, os livros didáticos continuam com espaço garantido na vida dos professores e estudantes (LEITE et al., 2012; PAVÃO; FREITAS, 2008).

Contudo, os resultados das investigações revelam que, se por um lado, já podem ser observadas mudanças positivas nos livros didáticos, em especial considerando a avaliação oficial realizada pelo PNLD, ${ }^{1}$ por outro, ainda há muito que fazer para que as coleções didáticas correspondam aos avanços conceituais e aos fundamentos da área de ciências (GÜLLICH; SILVA, 2013; RUPPENTHAL; SCHETINGER, 2013).

No que diz respeito especificamente às inter-relações CTS, estudos brasileiros sobre livros didáticos dos anos finais do ensino fundamental e do ensino médio mostram que, em geral, esses materiais deixam a desejar quanto às suas contribuições para a compreensão das dimensões sociais da ciência e da tecnologia (AMARAL; XAVIER; MACIEL, 2009; ARAÚJO, 2012; CANHETE, 2011; COSTA, 2013; FERNANDES, 2013; PASCHINI NETO, 2011; SALLA, 2016). Além disso, há livros que reforçam uma visão de ciência neutra, de processo científico isento de valores, interesses, conflitos e contradições (ARAÚJO, 2012) e há livros que veiculam concepções equivocadas acerca da ciência e imagens esteriotipadas do cientista, que acabam por disseminar ideias distorcidas da ciência e do empreendimento científico (GÜLLICH; SILVA, 2013).

Cabe destacar que no âmbito escolar, diante do pouco investimento e da insuficiência de processos formativos, além de servir de apoio às práticas de ensino, os livros didáticos desempenham, não raras vezes, um papel de "agentes de formação” (PINHÃO; MARTINS, 2013, p. 79), que podem colaborar para divulgar e encorajar práticas pedagógicas em consonância com os pressupostos CTS ou podem reforçar uma visão reducionista da ciência, da tecnologia e do seu ensino, como sinalizam pesquisadores como Carneiro, Santos e Mól (2005), Martins (2012) e Megid Neto e Fracalanza (2006).

Ademais, salienta-se que, embora em expansão no cenário brasileiro, as pesquisas sobre ensino de ciências com enfoque CTS nos anos iniciais ainda são incipientes (FERNANDES; MEGID NETO, 2016; MUJOL; LORENZETTI, 2016), de modo que os professores contam com poucas referências teórico-práticas de implementação das práticas CTS nos primeiros anos do ensino fundamental.

\section{METODOLOGIA}

Este estudo teve como objetivo analisar as possíveis abordagens relativas às dimensões sociais da ciência e da tecnologia em livros didáticos integrados de ciências humanas e da natureza, do $4^{\circ}$ ano do Ensino Fundamental. Em função disso, a abordagem metodológica foi de natureza qualitativa e optou-se pelo uso de técnicas de análise de conteúdo com base em Bardin (2011).

Em relação aos procedimentos técnicos, o estudo caracterizou-se como pesquisa documental, que “[...] é um procedimento que se utiliza de métodos e 
técnicas para a apreensão, compreensão e análise de documentos dos mais variados tipos" (SÁ-SILVA; ALMEIDA; GUINDANI, 2009).

Os documentos analisados neste trabalho foram os livros didáticos dos professores do $4^{\circ}$ ano do ensino fundamental, de ciências humanas e da natureza, avaliados e aprovados pelo PNLD, referentes ao triênio 2016-2018. Cabe mencionar que do processo de avaliação do PNLD 2016 foram aprovadas três coleções de ciências humanas e da natureza. Portanto, no âmbito deste estudo, foram investigados três livros didáticos, a saber: Ligados.com Ciências Humanas e da Natureza, da editora Saraiva; Porta Aberta, da editora FTD e o livro Projeto Buriti Ciências Humanas e da Natureza, da editora Moderna.

De acordo com Gil (2008, p. 51), “a pesquisa documental assemelha-se muito à pesquisa bibliográfica. A única diferença entre ambas está na natureza das fontes". Na bibliográfica, o pesquisador faz uso das contribuições de materiais já elaborados por diversos autores, principalmente livros e artigos científicos, sobre o assunto. $\mathrm{Na}$ documental, a fonte de coleta de dados está circunscrita a documentos "que não receberam ainda um tratamento analítico, ou que ainda podem ser reelaborados de acordo com os objetivos da pesquisa”.

Com base nos princípios propostos por Bardin (2011), a pesquisa foi desenvolvida a partir das seguintes etapas: I) escolha dos documentos a serem submetidos aos procedimentos analíticos; II) elaboração da matriz de análise; III) pré-teste de análise e validação da matriz; IV) exploração do material e V) interpretação e discussão.

Para a construção da matriz de análise utilizou-se como referência o instrumento criado por Fernandes (2011), para uma investigação quanto à perspectiva CTS em livros escolares de ciências; os descritores para análise de livros didáticos elaborados por Amaral et al. (2006); os nove aspectos que caracterizam o enfoque CTS, extraídos de Mackavanagh e Maher (1982), traduzidos por Santos e Schnetzler (2010); e os parâmetros de racionalidade científica, desenvolvimento tecnológico e participação social, elaborados por Strieder (2012), especialmente os níveis de compreensão de participação social no contexto da educação científica. O quadro 1 apresenta a matriz de análise elaborada. 
Quadro 1. Matriz de análise

\begin{tabular}{|c|c|c|}
\hline Dimensões & Categorias & Indicadores \\
\hline \multirow[t]{2}{*}{$\begin{array}{l}\text { A - Apre- } \\
\text { sentação do } \\
\text { conteúdo }\end{array}$} & $\begin{array}{l}\text { I) Natureza } \\
\text { da prática } \\
\text { científico- } \\
\text {-tecnológica }\end{array}$ & $\begin{array}{l}\text { A1-Contextualiza historicamente o processo de produção } \\
\text { do conhecimento científico (explicita sua evolução, êxitos } \\
\text { e fracassos e indica o seu contexto sociocultural, político } \\
\text { e econômicol. } \\
\text { A2-Apresenta a produção do conhecimento científico- } \\
\text {-tecnológico como atividade social que envolve muitos } \\
\text { sujeitos e instituições. } \\
\text { A3-Relata pesquisas já concluídas explicitando os méto- } \\
\text { dos científicos utilizados, esclarecendo as etapas e o por- } \\
\text { quê das decisões tomadas, apresentando os resultados e } \\
\text { os usos pela sociedade. } \\
\text { A4-Relata pesquisas em andamento explicitando as ra- } \\
\text { zões que motivaram a investigação do problema, as in- } \\
\text { certezas e as implicações sociais envolvidas. } \\
\text { A5-Apresenta o conhecimento científico como uma, entre } \\
\text { outras formas de conhecimento, sem tratá-lo com supre- } \\
\text { macia absoluta. } \\
\text { A6-Contextualiza o processo de produção tecnológica } \\
\text { destacando seu caráter social. } \\
\text { A7-Aponta que a tecnologia envolve a utilização do conhe- } \\
\text { cimento científico e técnico para a resolução de proble- } \\
\text { mas; a tecnologia não é vista como aplicação da ciência. } \\
\text { A8-Apresenta a tecnologia como uma atividade humana, } \\
\text { como prática que engloba aspectos técnicos, organizacio- } \\
\text { nais e culturais. } \\
\text { A9-Mostra que os conhecimentos científico-tecnológicos } \\
\text { se inter-relacionam, sendo que o conhecimento científico } \\
\text { pode contribuir para o desenvolvimento tecnológico. } \\
\text { A10-Aponta que os conhecimentos científico-tecnológi- } \\
\text { cos se inter-relacionam, sendo que os conhecimentos e } \\
\text { recursos tecnológicos podem contribuir para a produção } \\
\text { e avanço do conhecimento científico. } \\
\text { A11-Apresenta diversos argumentos e pontos de vista so- } \\
\text { bre questões relativas à ciência e à tecnologia. } \\
\text { A12-Aponta relações de poder, interesses e contradições } \\
\text { que se fazem presentes no processo de produção da ciên- } \\
\text { cia e da tecnologia. }\end{array}$ \\
\hline & $\begin{array}{l}\text { II) Natureza } \\
\text { da } \\
\text { Sociedade }\end{array}$ & $\begin{array}{l}\text { A13-Mostra a sociedade como uma instituição humana, } \\
\text { com diferentes culturas e valores. } \\
\text { A14-Expressa que a sociedade é constituída por diversas } \\
\text { organizações, associações, instituições públicas e } \\
\text { privadas, empresas, grupos organizados, cidadãos } \\
\text { comuns. } \\
\text { A15-Aponta que na sociedade ocorrem mudanças } \\
\text { científico-tecnológicas. }\end{array}$ \\
\hline
\end{tabular}




\begin{tabular}{|c|c|c|}
\hline Dimensões & Categorias & Indicadores \\
\hline $\begin{array}{l}\text { A - Apre- } \\
\text { sentacção do } \\
\text { conteúdo }\end{array}$ & $\begin{array}{l}\text { III) Influên- } \\
\text { cias CTS }\end{array}$ & $\begin{array}{l}\text { A16-Mostra que o desenvolvimento científico-tecnológico } \\
\text { pode influenciar o pensamento, as resoluções dos pro- } \\
\text { blemas e o estilo de vida das pessoas. } \\
\text { A17-Aborda a ciência e a tecnologia não como propulsoras } \\
\text { absolutas do progresso social e nem como as únicas res- } \\
\text { ponsáveis pelos problemas que a humanidade enfrenta. } \\
\text { A18-Fornece exemplos de tecnologias presentes no coti- } \\
\text { diano e/ou evidencia a utilidade social da ciência. } \\
\text { A19-Explora tópicos de temas/problemas científico-tec- } \\
\text { nológicos de modo a informar/aproximar a sociedade da } \\
\text { ciência e da tecnologia. } \\
\text { A20-Aborda aspectos positivos e negativos relativos ao } \\
\text { uso de um determinado resultado/produto científico-tec- } \\
\text { nológico, em contexto individual/local. } \\
\text { A21-Discute as implicações sociais lambientais, políticas, } \\
\text { econômicas, históricas, éticas, psicológicas, culturais) } \\
\text { mais amplas da ciência e da tecnologia, em diferentes } \\
\text { contextos. } \\
\text { A22-Aponta relações de poder, valores e interesses de } \\
\text { certos grupos sociais e contradições no processo de pro- } \\
\text { dução da ciência e da tecnologia, evidenciando a neces- } \\
\text { sidade/possibilidade de mecanismos de controle social. } \\
\text { A23-Aborda acerca da participação da sociedade no con- } \\
\text { texto das esferas políticas; enfatiza interesses coletivos e } \\
\text { desenvolvimento científico-tecnológico em conformidade } \\
\text { com as necessidades do contexto social. }\end{array}$ \\
\hline $\begin{array}{l}\text { B - Encami- } \\
\text { nhamentos } \\
\text { Metodo- } \\
\text { lógicos e } \\
\text { Atividades } \\
\text { Propostas }\end{array}$ & $\begin{array}{l}\text { IV) Propos- } \\
\text { tas para a } \\
\text { compreen } \\
\text { são das } \\
\text { inter-rela- } \\
\text { ções CTS }\end{array}$ & $\begin{array}{l}\text { B1-Propõe atividades diversificadas que estimulem o } \\
\text { estudante a expressar ideias e opiniões, pesquisar, co- } \\
\text { nhecer outras opiniões e argumentos, discutir e com- } \\
\text { partilhar pontos de vista, refletir, observar, argumentar, } \\
\text { dar explicações, analisar e confrontar diferentes visões e } \\
\text { argumentos, sobre aspectos sociais relativos à ciência e } \\
\text { à tecnologia, favorecendo o desenvolvimento de atitudes, } \\
\text { valores e pensamento crítico. } \\
\text { B2-Propõe a realização de atividades investigativas para } \\
\text { explorar, compreender e avaliar as inter-relações CTS. } \\
\text { B3-Apresenta propostas que envolvam o estudante em pro- } \\
\text { jetos que favoreçam o desenvolvimento do pensamento crí- } \\
\text { tico sobre questões sociais relativas à ciência e à tecnologia. } \\
\text { B4-Propõe o envolvimento em assuntos comunitários, de } \\
\text { modo a desenvolver no estudante o interesse e a postura } \\
\text { de comprometimento com a busca e a construção coletiva } \\
\text { de possíveis alternativas para os problemas reais do seu } \\
\text { contexto. } \\
\text { B5-Apresenta propostas que estimulem o estudante a apli- } \\
\text { car os conhecimentos adquiridos, envolvendo-se em acções } \\
\text { individuais ou coletivas, assumindo compromissos enquan- } \\
\text { to sujeitos corresponsáveis pelo próprio meio em que vivem. }\end{array}$ \\
\hline
\end{tabular}

Fonte: Autoria própria 
Para verificar a abordagem CTS nos livros didáticos optou-se em proceder à análise contemplando todas as unidades de ensino dos livros e verificando-se tanto os textos de conteúdos para os estudantes, quanto os de orientações didáticometodológicas para os professores, os textos de apoio e as atividades propostas. Sendo assim, o estudo contemplou duas dimensões de análise: dimensão A referente aos textos de apresentação de conteúdo; e dimensão B - relativa aos encaminhamentos metodológicos e atividades propostas nos livros.

A dimensão de análise A foi organizada em três categorias: natureza da prática científico-tecnológica (expressa nos indicadores A1 a A12); natureza da sociedade (indicadores A13 a A15); e influências CTS (indicadores A16 a A23). A dimensão de análise B foi estruturada em uma única categoria: propostas para a compreensão das inter-relações CTS (expressa nos indicadores B1 a B5). A partir dessas categorias, foram delimitados os indicadores, entendidos como um conjunto de características que constituem as categorias.

Para a sua validação, a matriz de análise foi submetida à avaliação de três especialistas com conhecimentos na área específica e titulação de doutorado, que analisaram o instrumento quanto a sua adequação, considerando o referencial teórico CTS e os propósitos do estudo.

Para essa avaliação, os especialistas receberam uma sinopse da pesquisa e a matriz de análise em sua primeira versão. Cada avaliador emitiu um parecer sobre o instrumento, a partir de questionamentos sobre o seu conteúdo. Várias modificações foram realizadas na matriz de análise a partir das sugestões dos pareceres, de modo que categorias foram reorganizadas, alguns indicadores foram excluídos e outros reformulados e/ou complementados.

$\mathrm{Na}$ etapa de exploração do material, leituras minuciosas foram feitas para a seleção de trechos de interesse, os quais passaram pelo procedimento de recorte de unidade de contexto, e passaram a compor o material de análise. As unidades de contexto foram constituídas por fragmentos (frases, parágrafos, conjunto de parágrafos, enunciados das atividades, etc.) que traziam marcas ou indícios, explícitos (E) ou implícitos (I) das interações CTS, tendo como referência os indicadores da matriz de análise.

Marcas ou indícios, explícitos (E) ou implícitos (I), são indícios textuais presentes nos materiais analisados, por exemplo, termos, palavras ou frases que apresentam relações com os indicadores da matriz de análise, sinalizando a abordagem do livro quanto às relações CTS.

Os indícios implícitos são aqueles que sinalizam uma relação com um dos indicadores, mas essa relação não está claramente expressa, ficando apenas subentendida no texto. Portanto, não evidenciam suficientemente as inter-relações CTS, de modo a contribuir para sua compreensão, todavia, apresentam-se como trechos potenciais, que se bem explorados pelos professores, podem colaborar para o entendimento das interrelações CTS. Por sua vez, as marcas ou indícios que manifestam evidências claras de aspectos CTS são identificados como trechos explícitos.

Para complementar o processo analítico dos livros didáticos, foi realizada uma análise quantitativa, pautada na frequência com que os indicadores da matriz apareceram nos livros analisados. A seguir, apresentam-se alguns dos principais resultados obtidos e a discussão dos dados. 


\section{RESULTADOS E DISCUSSÃO}

Em uma análise geral da proximidade ou distanciamento dos livros didáticos estudados em relação a abordagem dos aspectos CTS, pode-se destacar que se verificaram evidências de aspectos CTS em todos os livros.

Contudo, a partir de uma análise pormenorizada constataram-se diferentes níveis de profundidade de discussão; alguns indicadores foram contemplados em um número muito reduzido de episódios, relativamente à totalidade de páginas analisadas; outros tiveram uma presença exígua, e outros ainda, não contaram com qualquer referência nos livros pesquisados.

Dos 23 indicadores da matriz de análise, referentes aos textos de apresentação de conteúdo (dimensão A), foram encontrados nos livros estudados, referências de 19 indicadores. Enquanto alguns indicadores foram localizados com certa frequência, outros foram negligenciados ou totalmente deixados de lado, como exposto no quadro 2.

Quadro 2. Frequência de indicadores explícitos e implícitos da dimensão A em cada livro

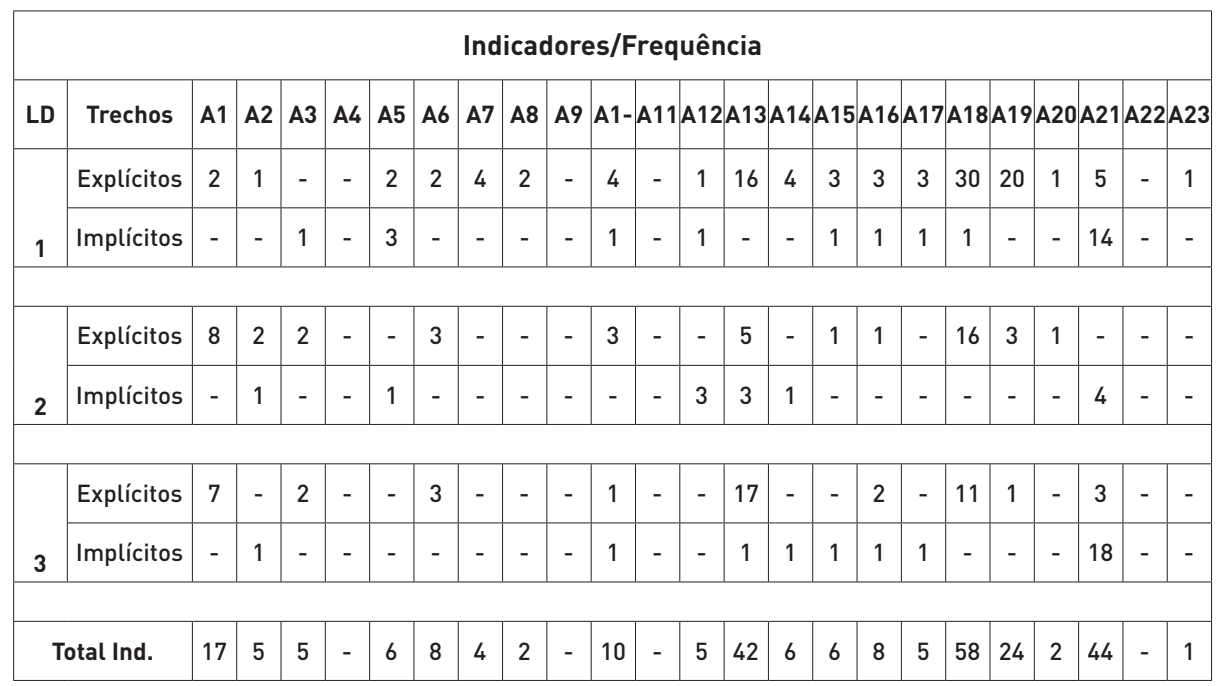

Fonte: Autoria própria com base nos dados da pesquisa

Considerando-se as ocorrências explícitas e implícitas nos livros, constatou-se que os livros didáticos analisados privilegiaram em sua abordagem:

a) a referência a exemplos da presença da ciência e da tecnologia no dia a dia (indicador A18, com 58 trechos identificados, com destaque nos três livros analisados);

b) as repercussões do uso da ciência e da tecnologia (indicador A21, com 44 trechos identificados, com ênfase em dois dos três livros investigados); 
c) o reconhecimento da diversidade cultural da sociedade contemporânea (indicador A13, valorizado nos três livros estudados, com um total de 42 episódios identificados).

Os demais indicadores tiveram um pequeno número de representações em cada livro estudado. O quadro 2 exibe que o indicador A8, por exemplo, foi encontrado somente no LD1, com apenas duas inserções. Referências ao indicador A20 foram encontradas nos livros 1 e 2, entretanto, com apenas um trecho identificado em cada livro. Por sua vez, o indicador A23 foi localizado apenas no livro 1, com uma menção identificada.

Esses indicadores (A8, A20 e A23) correspondem à aspectos importantes para uma compreensão crítica a respeito da ciência e da tecnologia, pois se referem, respectivamente: a apresentação da tecnologia como atividade humana, que engloba aspectos técnicos, organizacionais e culturais; aspectos positivos e negativos relativos ao uso de um determinado resultado ou produto científicotecnológico; e participação da sociedade no contexto das esferas políticas, em processos decisórios que envolvem ciência e tecnologia.

Outros aspectos relevantes que estiveram ausentes dos livros didáticos analisados, foram os relacionados aos indicadores:

- A4 - relata pesquisas em andamento explicitando as razões que motivaram a investigação do problema, as incertezas e as implicações sociais envolvidas;

- A9 - mostra que os conhecimentos científico-tecnológicos se inter-relacionam, sendo que o conhecimento científico pode contribuir para o desenvolvimento tecnológico;

- A11 - apresenta diversos argumentos e pontos de vista sobre questões relativas à ciência e à tecnologia; e

- A22 - aponta relações de poder, valores e interesses de certos grupos sociais e contradições no processo de produção da ciência e da tecnologia, evidenciando a necessidade/possibilidade de mecanismos de controle social.

Por um lado, pode-se afirmar que os livros didáticos estudados enfatizaram elementos importantes, pois incluíram aspectos culturais da sociedade, destacandose sua diversidade; apresentaram vários exemplos da presença da ciência e da tecnologia no meio social, bem como mostraram benefícios que elas trazem.

Por outro lado, ressalta-se a necessidade de avançar nessas discussões. Não basta que o aluno identifique a presença da ciência e da tecnologia no meio social, pois essa identificação, sem uma apreciação crítica quanto aos seus processos, riscos e implicações sociais, traz subjacente um entendimento de tecnologia enquanto simples aparato livre de influências sociais, utilizado para satisfação das necessidades humanas.

Por sua vez, apenas o reconhecimento das repercussões positivas da ciência e da tecnologia, sem uma reflexão crítica, pode conduzir a uma concepção linear 
de desenvolvimento científico-tecnológico, na qual está presente uma visão de que mais ciência e mais tecnologia produzirão, necessariamente, mais bem-estar social (STRIEDER, 2012).

Além disso, a identificação de impactos da ciência e da tecnologia no meio social, sem uma discussão crítica sobre eles e sem a percepção de que materializam determinados interesses e propósitos, pode levar a um entendimento limitado, passando uma ideia fatalista de que não há o que fazer, a não ser tentar lidar com as consequências de um produto já pronto e posto em uso no meio social, conforme sinalizam os estudos de Auler (2011), Rosa e Auler (2016), Santos (2016) e Strieder (2012).

Relativamente aos encaminhamentos metodológicos e atividades propostas nos livros didáticos, observou-se que os 5 indicadores da dimensão B da matriz de análise foram encontrados nos livros investigados. Entretanto, verificou-se uma presença expressiva de propostas condizentes com o indicador B1, comparativamente as propostas identificadas em outros grupos da dimensão $\mathrm{B}$ de análise, como pode ser observado no quadro 3.

Quadro 3. Frequência de indicadores explícitos e implícitos da dimensão B em cada livro

\begin{tabular}{|c|c|c|c|c|c|c|}
\hline \multicolumn{7}{|c|}{ Indicadores/Frequência } \\
\hline \multirow{2}{*}{ LD } & Trechos & B1 & B2 & B3 & B4 & B5 \\
\hline \multirow{2}{*}{1} & Explícitos & 9 & - & - & - & 1 \\
\cline { 2 - 8 } & Implícitos & 21 & - & - & 4 & 1 \\
\hline \multirow{2}{*}{2} & Explícitos & 5 & - & - & - & - \\
\cline { 2 - 8 } & Implícitos & 7 & - & - & - & - \\
\hline \multirow{2}{*}{3} & Explícitos & 8 & 1 & 1 & - & 1 \\
\cline { 2 - 8 } & Implícitos & 27 & 2 & 1 & 4 & - \\
\hline
\end{tabular}

Fonte: Autoria própria com base nos dados da pesquisa

Pela consulta ao quadro síntese 3, pode-se observar que atividades investigativas (correspondentes ao indicador B2), envolvimento em projetos sobre questões relativas à ciência e à tecnologia (B3) e proposições de envolvimento dos alunos na busca de alternativas para problemas reais do seu entorno (B4) ou a inclusão de propostas interferentes na realidade (B5) foram localizadas de modo pontual e sua presença não ocorreu em todos os livros.

Considerando-se os resultados em termos de categorias de análise, destaca-se que em relação à categoria "Natureza da prática científico-tecnológica" (que contempla os indicadores A1 a A12 da matriz de análise) verificou-se nos três livros didáticos pesquisados uma preocupação com a apresentação do conteúdo, do saber escolar. Inclusões quanto à origem e à contextualização histórica da 
ciência que levassem em conta o contexto sociocultural, econômico e político de sua produção, assim como, reflexões sobre a sua natureza, seus procedimentos, as motivações para os estudos e seus resultados tiveram poucas inserções.

Verificou-se nos livros analisados manifestações de uma visão de ciência objetiva, socialmente neutra, descontextualizada e a-problemática e constatouse uma omissão quanto às relações de poder, valores e interesses sociais que condicionam o seu fazer científico, sobretudo em dois dos três livros analisados (LD1 e LD2). À título de exemplo, segue um excerto retirado do LD1:

[...] a ciência constitui uma forma de conhecimento caracterizada pela objetividade e universalidade de suas premissas e de suas conclusões e pela ampla aceitação de seus métodos de investigação. Isso não quer dizer que os resultados de determinada pesquisa científica sejam inquestionáveis [...] (LD1, p. 282).

Nota-se que essa referência à atividade científica, apesar de reconhecer a provisoriedade da ciência, é reveladora de uma visão de ciência objetiva, apoiada no método científico e em princípios de aplicação universal. Tais características remetem à concepção tradicional ou herdada da ciência (BAZZO; VON LINSINGEN; PEREIRA, 2003, p.14), na qual “a ferramenta intelectual responsável por produtos científicos [...], é o chamado 'método científico'.

Ainda nos livros investigados, a falta de explicitação das inter-relações entre ciência, tecnologia e sociedade e a predominância da apresentação da tecnologia como simples ferramenta ou instrumento nos três livros analisados, sinalizaram uma ideia de desenvolvimento tecnocientífico neutro.

Via de regra, observou-se nos três livros didáticos analisados, inserções genéricas sobre os cientistas, como nos exemplos a seguir: "Os cientistas afirmam que no Universo existe um número muito grande de astros [...]” (LD1, p. 20); “Os vulcões ajudaram muito os cientistas a imaginarem como é o interior do nosso planeta [...]" (LD2, p. 86); “Tempos depois, os pesquisadores desconfiaram que as doenças podiam ser causadas por seres invisíveis a olho nu [...]” (LD3, p. 34).

Por um lado, essa abordagem genérica, sem atribuição da produção científica a um cientista específico, sinaliza uma ideia de que essa atividade não é realizada por um único sujeito, iluminado, que sozinho faz suas "descobertas". Por outro, ao não revelar quem são as pessoas que fazem ciência, quais razões motivaram o seu desejo de seguir carreira científica, quais as suas inquietações e interesses de pesquisa, deixa de desvelar um aspecto essencial: a ciência é feita por gente. Gente que possui crenças, valores, pontos de vistas e interesses diversos (HODSON, 1998). Além disso, a abordagem genérica identificada nos livros, traz uma ideia de ciência feita por homens, uma vez que os excertos enfatizam o gênero masculino.

No que tange à categoria de análise "Natureza da sociedade" (correspondente aos indicadores A13 a A15 da matriz de análise), constatou-se que os textos dos livros investigados privilegiaram uma abordagem que enfatizou o reconhecimento da sociedade como instituição humana, com diferentes culturas e valores (correspondente ao indicador A13).

Cabe destacar que os aspectos culturais abordados nos livros didáticos são importantes para que as crianças percebam a dinâmica das relações em sociedade, 
identifiquem-se com o contexto sociocultural mais próximo e aprendam a respeitar as diferentes culturas e valores.

Entende-se que esses aspectos podem ser abordados de maneira integrada à abordagem de situações e problemáticas da vida cotidiana atual, ligadas às questões científico-tecnológicas. Isso porque parte-se do entendimento de que a formação para a cidadania implica colocar os alunos diante de situações concretas envolvendo as relações recíprocas entre a ciência, a tecnologia e a sociedade, e isso pode ser implementado desde as primeiras experiências educacionais das crianças, conforme defendido por pesquisadores da área (CORDEIRO; SGARBI, 2016; FABRI; SILVEIRA, 2013; SASSERON; CARVALHO, 2008).

Um exemplo disso foi identificado no LD3, em um trecho no qual os docentes são orientados a abordar os aspectos culturais relacionados à imigração, trazendo à tona problemas atuais que necessitam ser problematizados e refletidos com os estudantes, tais como as causas da imigração e as atitudes de países que dificultam a vinda de imigrantes, além de questões ligadas ao preconceito.

A abordagem de aspectos de organização social (indicador A14), embora identificada com pouca frequência nos livros analisados, levantou questões relevantes, como ser observado no trecho a seguir:

Nas cidades são frequentes as lutas por melhores salários e condições de trabalho, que são geralmente organizadas por sindicatos de trabalhadores. Outras associações lutam por melhorias urbanas, como saneamento básico, iluminação pública, transporte de qualidade, segurança etc.

Há ainda organizações que atuam em vários países, defendendo causas de interesse de toda a humanidade. Entre elas, destacam-se as que defendem o meio ambiente, como o Greenpeace e o WWF (LD1, p. 167).

Nesse excerto, o LD1 apresenta possibilidades de organização social que viabilizam a defesa de interesses e necessidades da população. Ainda no LD1 foram identificados trechos que versaram sobre medidas para evitar o esgotamento dos recursos naturais, tais como a criação do Ibama e programas de educação ambiental promovidos por ONGs. Outra referência abordou sobre a Conferência da ONU sobre Ambiente Humano e a Conferência das Nações Unidas sobre o Meio Ambiente e Desenvolvimento (Rio+20). E um trecho que, ao abordar sobre o impacto ambiental da instalação de uma usina hidrelétrica, mencionou sobre a criação de uma organização - o Movimento dos Atingidos por Barragens $(\mathrm{MAB})$ - movimento organizado em prol daqueles que tiveram que abandonar suas residências e recomeçar a vida em outra localidade.

Considera-se que apresentar essas diferentes formas de organização social aos alunos favorece a compreensão de que o contexto social é composto pelo coletivo de distintos grupos sociais, os quais manifestam diferentes ideologias e defendem interesses igualmente diversos. É importante, sobretudo, para mostrar que cada grupo pode se posicionar diante de questões sociocientíficas e que as ações coletivas são mais efetivas para exercer pressão sobre governos na luta por um modelo societário que priorize a equidade social e a sustentabilidade ambiental. 
Nessa ótica, Hodson (2014) e Reis (2013) defendem que os alunos precisam aprender a participar socialmente e a promoção de exemplos de possibilidades e de ações bem sucedidas é uma estratégia importante.

Nas obras analisadas foram identificados poucos trechos que deram visibilidade para o fato de que na sociedade ocorrem mudanças científicotecnológicas (referente ao indicador A15). As referências encontradas, convergiram no sentido de apresentar ou orientar o professor para a apresentação de tecnologias do passado e tecnologias atuais, de modo a apontar as diferenças entre elas e as mudanças que causam na vida das pessoas. O trecho retirado do LD1 ilustra a presença desse indicador:

Há cem anos, não havia telefone celular, televisão nem forno de micro-ondas. Atualmente, muitas pessoas já se habituaram tanto com eles que não conseguem imaginar como seria seu dia a dia sem esses objetos. [...] Até o século XX, por exemplo, era comum a utilização do pilão para produzir pó de café. Hoje, essa técnica ainda é utilizada, mas a maioria das famílias prefere comprar o café já moído (LD1, p. 92).

Considera-se que inserções como essa são relevantes na medida em que podem auxiliar os alunos a perceberem o quanto as mudanças científicotecnológicas estão atreladas ao contexto social.

Quanto à categoria de análise "Influências CTS" (que contempla os indicadores A16 a A23), prevaleceu nos livros pesquisados uma abordagem centrada na apresentação de exemplos da presença da ciência e da tecnologia na sociedade, sem apreciação quanto aos seus benefícios, riscos ou repercussões. Em casos menos frequentes, observaram-se apontamentos sob o ponto de vista dos aspectos positivos das inovações científico-tecnológicas, conforme ilustram os exemplos a seguir:

A cisterna é uma tecnologia popular para a captação de água da chuva, onde a água que escorre do telhado da casa é captada pelas calhas e cai direto na cisterna, onde é armazenada [...] (LD1, p. 89).

Os navegadores se localizavam no mar usando a bússola, o quadrante, o sextante, o astrolábio e a balhestilha. Esses equipamentos indicavam o tempo e o local pela posição das estrelas e constelações, do Sol e dos pontos cardeais - Norte, Sul, Leste e Oeste (LD2, p. 28).

Esse tipo de abordagem, centrada no reconhecimento da presença da ciência e da tecnologia no meio social, com apresentação de juízo de valor sob o ponto de vista positivo das inovações científico-tecnológicas, ou, ainda, sem qualquer análise quanto aos seus benefícios, riscos e consequências negativas, traz subjacente uma ideia de desenvolvimento científico-tecnológico neutro, pois além de omitir os condicionantes sociais que influenciam a tecnociência, silenciam, também, a respeito do controle do ser humano sobre a ciência e a tecnologia. Isso pode levar a um entendimento de que ela não é humanamente controlada e está sempre orientada para servir à humanidade. 
Desse modo, os textos se aproximam de uma perspectiva determinista. Segundo Feenberg (2010b, p. 72), o determinismo tecnológico é pautado na ideia de que as tecnologias teriam "uma lógica funcional autônoma, que pode ser explicada sem se fazer referência à sociedade”. Nessa concepção, o ser humano não tem controle sobre a ciência e tecnologia; ao contrário, é ela que "molda a sociedade às exigências de eficiência e progresso". A tecnociência faz uso do conhecimento do mundo natural para servir ao ser humano. Nesse sentido, cada avanço é voltado a ele, para satisfazer suas necessidades ou estender suas faculdades (FEENBERG, 2010a, p. 59).

Nessa visão determinista, dispensa-se qualquer questionamento e forma de participação dos cidadãos. Considera-se somente a eficiência técnica no desenvolvimento científico-tecnológico; nenhuma outra dimensão (valores humanos, ambientais, financeiros, políticos, éticos, entre outros) é passível de discussão e consideração nessa perspectiva, de modo a potencializar a concentração de poder em detrimento da participação democrática (DAGNINO; SILVA; PADOVANNI, 2011). Ou seja, reforça o mito da neutralidade e superioridade do modelo de decisões tecnocráticas, como discutido por Auler (2002; 2011).

A suposta neutralidade da ciência e da tecnologia também foi observada nos livros didáticos, sobretudo nos LD1 e 3, sob outra perspectiva - o "instrumentalismo", que combina referências de controle humano e neutralidade de valor (DAGNINO; SILVA; PADOVANNI, 2011; FEENBERG, 2010a).

De acordo com Dagnino, Silva e Padovanni (2011), nessa concepção, a ciência e a tecnologia poderiam servir, indistintamente, a qualquer propósito ou projeto de sociedade. Sob o otimismo da perspectiva liberal-positivista, o seu controle, exercido externamente e após sua produção, seria suficiente para o atendimento das necessidades de todo coletivo social.

Essa concepção apareceu nas três obras estudadas, principalmente nos episódios identificados como correspondentes ao indicador A21. Os excertos apresentados, a seguir, são ilustrativos dessa abordagem:

Explique o significado dos termos renovável e não renovável. Ressalte que renovável não significa necessariamente que a exploração desse tipo de fonte de energia não apresente consequências negativas ao ambiente.

Explique aos alunos sobre o uso racional dos combustíveis fósseis, pois, além de ser um recurso não renovável, a queima desse combustível é responsável por grande parte da emissão de gases do efeito estufa na atmosfera, agravando o processo de aquecimento global.

Incentive os alunos a refletir sobre o impacto que causam no ambiente. Estimule-os a economizar energia elétrica por meio de ações simples, como desligar o computador quando não estiver usando, apagar a luz de um cômodo antes de sair dele, tomar banhos rápidos, entre outras atividades (LD1, p. 320).

Conversar com os alunos sobre o descarte do lixo em locais inadequados, o que causa o entupimento de canos e galerias e diminui a vazão de córregos e rios. Salientar a importância de cada cidadão, que pode contribuir com atitudes simples, como não jogar lixo no chão e em outros locais indevidos ou solicitar a coleta de lixo e a varrição de ruas junto à prefeitura (LD3, p. 231-232). 
Nos livros investigados predominou um tratamento limitado à referência de repercussões quanto às implicações da ciência e da tecnologia. Em todos os casos a abordagem da relação entre ciência, tecnologia e sociedade foi unidirecional: foram indicados impactos do desenvolvimento científico-tecnológico sobre a sociedade, mas omitiram-se a influência recíproca, ou seja, que a prática científicotecnológica é condicionada por fatores sociais, de modo que atende a interesses privados de determinados grupos sociais.

A perspectiva de participação social observada nos textos foi sempre relacionada à avaliação de efeitos pós-concepção, pós-produção científicotecnológica, predominantemente sob uma dimensão micro e pessoal, na qual sugeriram-se que os sujeitos, individualmente, deveriam buscar mecanismos para amenizar os impactos dos usos dos produtos/resultados científico-tecnológicos considerados negativos. Trata-se, portanto, de uma perspectiva de participação limitada e que pode comprometer a educação para a participação democrática, uma vez que se encontra apoiada em valores tecnocráticos (AULER, 2011).

Por outro lado, isso não quer dizer que essa perspectiva de participação não é válida. Ela é válida e necessária, pois contribui com questionamentos relevantes relacionados à ciência e à tecnologia (STRIEDER; KAWAMURA, 2014; ROSA, AULER, 2016). No que tange às práticas de ensino, “[...] muitas vezes representa a estratégia crítica possível de ser abordada diante de uma dada situação, com contribuições à inserção cidadã" (STRIEDER; KAWAMURA, 2014, p. 107).

Ainda que se observe a necessidade de avançar para compreensões mais críticas, os livros didáticos analisados apresentaram várias contribuições, como pode ser verificado no trecho a seguir, retirado do LD1. Ele ilustra uma abordagem que traz elementos interessantes quanto às implicações sociais da ciência e da tecnologia:

Qual o impacto ambiental da instalação de uma usina hidrelétrica?

É um estrago e tanto. $\mathrm{Na}$ área que recebe o grande lago que serve de reservatório da hidrelétrica, a natureza se transforma: o clima muda, espécies de peixes desaparecem, animais fogem para refúgios secos, árvores viram madeira podre debaixo da inundação. E isso fora o impacto social: milhares de pessoas deixam suas casas e têm de recomeçar sua vida do zero num outro lugar. No Brasil, 33 mil desabrigados estão nessa situação e até criaram uma organização, o Movimento dos Atingidos por Barragens (MAB). [...] se pensarmos no clima global, as termoelétricas - que funcionam queimando gás ou carvão - são as piores, pois lançam gases na atmosfera que contribuem para o efeito estufa. A verdade é que não existe nenhuma forma de geração de energia 100\% limpa. [...] Por causa disso, os ambientalistas defendem a bandeira da redução do consumo. [...] Isso evitaria que novas hidrelétricas precisassem ser construídas, protegendo um pouco mais nosso planeta (LD1 p. 229).

Nesse excerto, observam-se elementos para uma reflexão e discussão acerca das repercussões provocadas pela instalação de uma usina hidrelétrica. Há menções sobre impactos ambientais e também sociais; lembram que nenhuma forma de produção de energia é totalmente limpa e, ainda, citam o movimento dos ambientalistas em torno dessa problemática. Portanto, apresenta aspectos essenciais para um debate em torno das relações entre ciência, tecnologia e sociedade. 
Cabe salientar que os livros didáticos servem de apoio ao trabalho docente e não garantem que propostas com esse enfoque sejam concretizadas no contexto escolar. Uma prática pedagógica com enfoque CTS implica a apropriação pelo professor dos pressupostos teóricos e metodológicos dessa abordagem e sua transposição para a sala de aula.

Nesse sentido, materiais didáticos com orientação CTS representam uma contribuição significativa, mas é imprescindível a formação docente, como meio de construção coletiva de conhecimentos, de interação, diálogo e troca de experiências e de saberes docentes, que pode favorecer as mudanças necessárias nas práticas educativas.

Em relação aos encaminhamentos metodológicos e atividades sugeridas nos livros didáticos estudados, verificou-se que prevaleceram atividades que não incorporaram explicitamente aspectos CTS, todavia sinalizam propostas que potencialmente poderiam abordá-las.

Os trechos a seguir exemplificam uma forma comum de abordagem implícita de aspectos CTS identificada nos livros analisados:

Observe a foto da página ao lado [Figura de Córrego poluído] e responda às questões em seu caderno.

a) Qual sua primeira impressão dessa imagem?

b) Que elementos predominam na imagem?

c) Com base no que você vê na foto, identifique elementos naturais e os elementos introduzidos pelo ser humano.

d) Que atitudes poderiam evitar que essa cena acontecesse? (LD1, p. 60-61).

Converse com os colegas e responda: quais cuidados a indústria deve tomar para não prejudicar o meio ambiente? (LD2, p. 247).

Nota-se que a proposta supracitada, retirada do LD1, pouco estimula o senso de criticidade dos alunos em relação ao tema em pauta - a poluição. Focaliza somente sensibilizar os alunos no que diz respeito à imagem (poluição do córrego) e o que pode ser feito para amenizar impactos. Não há uma preocupação em levar os estudantes a identificar e refletir sobre quais são esses impactos e não se observa problematização a respeito do atual modelo de produção e consumo. Também não se verificam questionamentos que possam conduzir a uma reflexão acerca da necessidade da promoção de um novo estilo de desenvolvimento tecnológico, orientado por outros valores e por outros modos de produção, sustentado em bases ecológicas, como discutido por Carletto e Sant'Anna (2006).

A atividade sugerida no LD2 não estimula uma discussão sobre a produção industrial e seu modelo de produção e consumo, na qual há grande extração de recursos naturais e geração de impactos e resíduos. Essas relações entre produção de bens de consumo, sistema econômico com sua lógica e estratégias de mercado, bem como as implicações socioculturais ficaram ausentes na sugestão dessa atividade, assim como foram negligenciadas na grande maioria das propostas apresentadas nos livros didáticos analisados. 
Com menor frequência, verificaram-se propostas com aspectos CTS manifestados explicitamente, conforme ilustra o excerto a seguir:

1. Segundo o texto [Soando no vento], o vento vem sendo utilizado pelo ser humano para quê?

2. De que modo as turbinas eólicas geram energia?

3. Quais são as vantagens e desvantagens das usinas eólicas?

4. Você sabe por que a energia produzida nessas usinas é considerada energia limpa?

5. Em sua opinião, a instalação de usinas eólicas traz prejuízos ambientais? (LD1, p. 108).

Observa-se que essa proposta sugere um trabalho para a identificação de impactos do desenvolvimento tecnológico, o que contribui para a percepção de que a tecnologia não conduz, automaticamente, a uma vida melhor (BAZZO, 2014).

Outras atividades com desdobramentos interessantes, também foram localizadas no LD2, como pode ser verificado nos trechos a seguir. Esses excertos sugerem debates que trazem à tona características de uma visão de ciência mais real e humana, uma imagem de ciência não elitista, não sexista, restrita a minorias, sobretudo, homens e de pele branca:

Solicitar aos alunos que pesquisem a atuação de afrodescentes e indígenas brasileiros em diversos setores profissionais: Política, Pesquisa Científica, Medicina, Engenharia, Direito, entre outros (LD2, p. 323).

Estes dois filmes [Quase Deuses e Mãos talentosas] podem ser vistos pelos alunos para que, depois, realizem um debate sobre as relações étnico-raciais e reflitam por que cientistas afrodescentes foram excluídos das enciclopédias e nunca citados em livros didáticos. [...] Desmontar o mito que a Ciência é feita por homens brancos; promover a alteridade e combater o sexismo com os alunos (LD2, p. 323).

Embora localizadas de modo pontual nos livros analisados, propostas como essas podem ajudar os estudantes a entender a rede de relações que envolve a atividade científica e a compreender que a ciência é feita por sujeitos sóciohistóricos, que atuam em um campo produzido socioculturalmente.

De modo geral, as propostas sugeridas nos livros didáticos que abordaram aspectos CTS, apresentaram uma abordagem centrada nos impactos da tecnociência sobre o meio, sem problematizações a respeito dos processos, das práticas científico-tecnológicas e dos valores e interesses econômicos, políticos, culturais que as envolvem. Além disso, em sua maioria, as propostas identificadas pouco instigaram a criatividade, a sensibilidade, o posicionamento crítico e a mobilização dos estudantes no envolvimento com as problemáticas do entorno social.

Cabe destacar que esses resultados vão ao encontro de outras investigações sobre livros didáticos de ciências (AMARAL; XAVIER; MACIEL, 2009; ARAÚJO, 2012; CANHETE, 2011; COSTA, 2013; FERNANDES, 2013; PASCHINI NETO, 2011; SALLA, 2016), que mostram que os livros didáticos em circulação nas escolas brasileiras pouco têm contribuído para a compreensão crítica das inter-relações CTS e para a formação de sujeitos científica e tecnologicamente alfabetizados. 
Diante disso, um ponto que merece destaque é o necessário investimento em formação docente. Como lembram Manassero, Vázquez e Acevedo (2001), o professor ensina aquilo que ele entende. Se ele tiver uma compreensão inadequada a respeito da ciência e da tecnologia, ligada a concepções ingênuas, a mitos, poderá ensinar o aluno a ter uma compreensão diferente?

Nesse aspecto, Carletto (2009, p. 23) reforça que as crenças e as compreensões que os professores possuem “[...] é que determinam e guiam suas práticas pedagógicas [...], facilitando ou impedindo determinadas aprendizagens". Assim, a formação docente é uma necessidade premente e essencial para a construção de um entendimento mais crítico sobre as relações CTS, bem como para a construção de práticas pedagógicas em consonância com essa perspectiva.

\section{CONSIDERACְÕES FINAIS}

Os resultados deste estudo revelaram que as inter-relações CTS possuem um espaço pouco expressivo nos livros didáticos analisados, considerando os livros em sua totalidade e a frequência com que os aspectos CTS foram contemplados nesses materiais.

O modo como as inter-relações CTS foram abordadas reflete uma visão de ciência e tecnologia socialmente neutras. Os textos de conteúdos, as atividades e as orientações didáticas presentes nos livros pesquisados não fomentam o entendimento amplo e crítico das recíprocas relações CTS; não colocam em discussão quais são os valores que embasam a produção científico-tecnológica, nem a importância de que esta esteja em consonância às necessidades e aos interesses coletivos.

Por outro lado, os livros analisados manifestaram iniciativas importantes de inserção de aspectos CTS, sobretudo no que refere ao reconhecimento da presença da ciência e da tecnologia, da diversidade cultural da sociedade contemporânea e da identificação de benefícios e impactos negativos do desenvolvimento científicotecnológico.

Salienta-se que o livro didático representa apenas um apoio, constituise como mais um instrumento entre vários outros. Todavia o livro apresenta e reafirma concepções, tanto para os estudantes, quanto para os professores. Desse modo, sugere-se a incorporação crítica e ampliada das inter-relações CTS nos livros didáticos dos anos iniciais, a fim de que possam melhor subsidiar o ensino de ciências com enfoque CTS no contexto dos anos iniciais do Ensino Fundamental.

Considera-se que, por si só, nenhum material didático garantirá a concretização de propostas de ensino coerentes com os pressupostos CTS. O fazer educativo está atrelado às concepções que os docentes possuem, aos conhecimentos que eles têm sobre as relações CTS, aos pressupostos metodológicos necessários à sua transposição didática, à segurança e ao interesse para tratar de temas sociocientíficos. Por outro lado, entende-se que os livros didáticos têm uma contribuição importante a dar, no sentido de servir de apoio acerca das possibilidades de ensino comprometidas com as dimensões sociais, que estão imbricadas na produção do conhecimento científico-tecnológico. 
Nessa perspectiva, a incorporação das inter-relações CTS nos livros didáticos configura-se como uma estratégia importante e necessária, que precisa ser aliada ao investimento em políticas públicas de formação docente contínua e consistente, nas quais sejam privilegiadas a interação, o diálogo, a reflexão e o apoio de professores formadores na concretização de um ensino mais crítico em relação às dimensões sociais do desenvolvimento científico-tecnológico.

\section{REFERÊNCIAS}

AMARAL, C. L. C.; XAVIER, E. da S.; MACIEL, M. de L. Abordagem das relações Ciência/ Tecnologia/Sociedade nos conteúdos e funções orgânicas em livros didáticos de Química do ensino médio. Investigações em Ensino de Ciências, v. 14, n.1, p.101-114, 2009. Disponível em: https:// www.if.ufrgs.br/cref/ojs/index.php/ienci/article/view/412/243. Acesso em: 10 mar. 2018.

AMARAL, I. A. do. et al. Avaliando livros didáticos de Ciências: análise de coleções didáticas de Ciências de $5^{\mathrm{a}}$ a $8^{\mathrm{a}}$ séries do Ensino Fundamental. In: FRACALANZA, H.; MEGID NETO, J. (org.). O livro didático de ciências no Brasil. Campinas: Komedi, 2006, p. 199-216.

ARAÚJO, M. M. S. Biotecnologia e cidadania: caraterísticas e reelaboração discursiva dos textos informativos científicos. 2012. 103 f. Dissertação (Programa de Mestrado em Educação) Universidade Federal de Uberlândia, Uberlândia, 2012.

AULER, D. Enfoque ciência-tecnologia-sociedade: pressupostos para o contexto brasileiro. Ciência e Ensino, v. 1, n. especial, p. 1-20, nov. 2007. Disponível em:http://www.ige.unicamp.br/ojs/index. php/cienciaeensino/article/download/147/109. Acesso em: 11 nov. 2018.

AULER, D. Interações entre Ciência-Tecnologia-Sociedade no contexto da formação de professores de ciências. 2002. Tese (Doutorado em Educaçao) - Centro de Educação, Universidade Federal de Santa Catarina, Florianópolis, 2002.

AULER, D. Novos caminhos para a educação CTS: ampliando a participação. In: SANTOS, W. L. P. dos; AULER, D. (org.). CTS e educação científica: desafios, tendências e resultados de pesquisas. Brasília: Editora Universidade de Brasília, 2011, p. 73-97.

BARDIN, L. Análise de conteúdo: edição revista e ampliada. Tradução de Luis Antero Neto e Augusto Pinheiro. São Paulo: Edições Setenta, 2011.

BAZZO, W. A. Ciência, tecnologia e sociedade e o contexto da educação tecnológica. $4^{a}$ ed. Florianópolis: UFSC, 2014.

BAZZO, W. A.; PEREIRA, L. T. do V.; BAZZO, J. L. dos S. Conversando sobre educação tecnológica. Florianópolis: Ed. da UFSC, 2014.

BAZZO, W. A.; VON LINSINGEN, I.; PEREIRA, L. T. V. (ed.) Introdução aos estudos CTS (Ciência, Tecnologia e Sociedade). Madrid: OEI, 2003.

CACHAPUZ, A. F. Tecnociência, poder e democracia. In: SANTOS, W. L. P. dos; AULER, D. (org.). CTS e educação científica: desafios, tendências e resultados de pesquisas. Brasília: Universidade de Brasília, 2011, p. 49-72.

CANHETE, M. V. U. Os PCNs e as inovações nos livros didáticos de Ciências. 2011. 93 f. Dissertação (Mestrado em Educação), Universidade Federal do Paraná, Curitiba, 2011. 
CARLETTO, M. R. Avaliação de impacto tecnológico: alternativas e desafios para a educação crítica em engenharia. 2009. Tese (Doutorado em Educação Científica e Tecnológica) - Programa de Pós-Graduação em Educação Científica e Tecnológica, Universidade Federal de Santa Catarina, Florianópolis, 2009.

CARLETTO, M. R.; SANT’ANNA, F. S. P. Desenvolvimento sustentável: limitações e possibilidades. In: V SIMPÓSIO INTERNACIONAL DE QUALIDADE AMBIENTAL, 5., 2006, Porto Alegre. Anais ... Porto Alegre: ABES, 2006. v. 1. p. 1-9.

CARNEIRO, M. H. S.; SANTOS, W. L. P.; MÓL, G. S. Livro didático inovador e professores: uma tensão a ser vencida. Ensaio: Pesquisa em Educação em Ciências, v.7, n. 2, p. 101-113, 2005. Disponível em: http://www.scielo.br/scielo.php?pid=S1983-21172005000200101\&script=sci_ abstract\&tlng=pt. Acesso em: 15 jun. 2018.

CORDEIRO, R. V.; SGARBI, A. D. Práticas pedagógicas que incluem CTS nos anos iniciais: bases para (des)construir o currículo. Indagatio Didactica. v. 8, n.1, p.1750-1765, jul. 2016. Disponível em: http://revistas.ua.pt/index.php/ID/article/view/3966/3648. Acesso em: 14 out. 2018.

COSTA, E. A. Análise de livros didáticos de biologia do ensino médio quanto ao tema "poluição" numa perspectiva CTS/CTSA. 2013. 96 f. Dissertação (Mestrado em Ensino de Ciências) - Universidade Cruzeiro do Sul, São Paulo, 2013.

DAGNINO, R. P. Uma estória sobre Ciência e Tecnologia, ou começando pela extensão universitária... In: DAGNINO, R. (org.). Estudos sociais da ciência e tecnologia e política de ciência e tecnologia: abordagens alternativas para uma nova América Latina. Campina Grande: EDUEPB, 2010. p. 293-324.

DAGNINO, R.; SILVA, R. B. da; PADOVANNI, N. Por que a educação em ciência, tecnologia e sociedade vem andando devagar? In: SANTOS, W. L. P.; AULER, D. (org.). CTS e educação científica: desafios, tendências e resultados de pesquisas. Brasília: Editora Universidade de Brasília, 2011, p. 99-134.

FABRI, F.; SILVEIRA, R. M. C. F. Ensino de ciências nos anos iniciais do ensino fundamental sob a ótica cts.: uma proposta de trabalho diante dos artefatos tecnológicos que norteiam o cotidiano dos alunos. Investigações em Ensino de Ciências, Porto Alegre, v.8, n.1, p. 77-105, 2013. Disponível em: http://www.if.ufrgs.br/ienci/artigos/Artigo_ID321/v18_n1_a2013.pdf Acesso em: 10 ago. 2018.

FEENBERG, A. O que é filosofia da tecnologia? In: NEDER, R. T. (Org.) A teoria crítica de Andrew Feenberg: racionalização democrática, poder e tecnologia. Brasília: Observatório do Movimento pela Tecnologia Social na América Latina. CDS, UnB, Capes, 2010a, p.49-65.

FEENBERG, A. Racionalização subversiva: tecnologia, poder e democracia. In: NEDER, R. T. (org.) A teoria crítica de Andrew Feenberg: racionalização democrática, poder e tecnologia. Brasília: Observatório do Movimento pela Tecnologia Social na América Latina. CDS, UnB, Capes, 2010b, p.68-95.

FERNANDES, I. M. B. A perspectiva CTSA nos manuais escolares de ciências da natureza do $2^{\circ}$ CEB. 2011. (Dissertação) - Instituto Politécnico de Bragança - Escola Superior de Educação de Bragança, Bragança, 2011.

FERNANDES, J. P. O tema energia e a relação Ciência-Tecnologia-Sociedade (CTS) presente no livro didático de física e no Exame Nacional do Ensino Médio. 2013. (Dissertação) - Núcleo de Tecnologia Educacional para a Saúde (NUTES), Universidade Federal do Rio de Janeiro, Rio de Janeiro, 2013. 
FERNANDES, R. C. A.; MEGID NETO, J. Práticas pedagógicas no ensino de ciências dos anos iniciais: um estudo a partir de pesquisas acadêmicas brasileiras. Indagatio Didactica, v. 8, n.1, p.1162-1176, 2016. Disponível em: http://revistas.ua.pt/index.php/ID/issue/view/283. Acesso em: 20 mar. 2017.

FERNANDEZ, P. M.; SILVA, D. O. Descrição das noções conceituais sobre os grupos alimentares por professores de $1^{a}$ a $4^{a}$ série: a necessidade de atualização dos conceitos. Ciência \& Educação, v. 14, n. 3, p.45-66, 2008. Disponível em: https://www.redalyc.org/pdf/2510/251019504006.pdf. Acesso em: 15 jun. 2019.

FREIRE, P. Pedagogia da autonomia. 21ª ed. São Paulo: Paz e Terra, 2002.

FREIRE, P. Pedagogia do Oprimido. 17ª ed. Rio de Janeiro: Paz e Terra, 2003.

FREIRE, P. Ação cultural para a liberdade e outros escritos. 11ª ed. São Paulo: Paz e Terra, 2006.

GIL, A. C. Métodos e técnicas de pesquisa social. 6ª ed. São Paulo: Atlas, 2008.

GÜLLICH, R. I. C.; SILVA, L. H. A. O enredo da experimentação no livro didático: construção de conhecimentos ou reprodução de teorias e verdades científicas? Revista Ensaio, Belo Horizonte, v. 15, n. 02, p. 155-167, maio/ago. 2013. Disponível: http://www.scielo.br/pdf/epec/v15n2/19832117-epec-15-02-00155.pdf. Acesso em: 11 abr. 2018.

HODSON, D. Teaching and Learning Science: Towards a Personalized Approach. Buckingham: Open University, 1998.

HODSON, D. Becoming Part of the Solution: Learning about Activism, Learning through Activism, Learning from Activism. In: BENCZE, L.; ALSOP, S. (Eds.). Activist Science and Technology Education. Springer, 2014, p. 67-98.

LEITE, L. et. al. Questionamento em manuais escolares de ciências: desenvolvimento e avaliação de uma grelha de análise. Educar em Revista, Curitiba, v. 44, p. 127-143, abr./jun. 2012. Disponível em: https://www.redalyc.org/html/1550/155023661009/. Acesso em: 11 abr. 2017.

MANASSERO, M. A.; VÁZQUEZ, A. ACEVEDO, J. A. Avaluació dels temes de ciència, tecnologia I societat. Illes Balears, Conselleria d'Educació i Cultura del Govern de les Illes Balears, 2001.

MARQUES, A. R. L.; REIS, P. Producción y difusión de vídeos digitales sobre contaminación ambiental. Estudio de caso: Activismo colectivo basado en la investigación. Revista Eureka sobre Enseñanza y Divulgación de las Ciencias, v. 14, n. 1, p. 215-226, 2017. Disponível em: https:// revistas.uca.es/index.php/eureka/article/view/3011/3033. Acesso em: 22 jun. 2018.

MARTINS, I. Analisando livros didáticos na perspectiva dos estudos de discurso: compartilhando reflexões e sugerindo uma agenda para a pesquisa. In: MARTINS, I.; GOUVÊA, G.; VILANOVA, R. O livro didático de ciências: contextos de exigência, critérios de seleção práticas de leitura e uso em sala de aula. Rio de Janeiro, 2012, p. 9-30. Disponível em: http:/ / www.nutes.ufrj.br/arquivos/O_ livro_didatico_de_Ciencias.pdf. Acesso em 10 mar. 2018.

MCKAVANAGH, C.; MAHER, M. Chalenges to science education and the STS response. The Australian Science Teachers Journal, v. 28, n. 2, p. 69-73, 1982.

MEGID NETO, J.; FRACALANZA, H. O livro didático de ciências: Problemas e soluções. In: FRACALANZA, H.; MEGID NETO, J. (org.). O livro didático de ciências no Brasil. Campinas: Komedi, 2006, p. 155-171. 
MEGID NETO, J.; ROCHA, M. B. Práticas de formação de professores para o ensino de ciências nos anos iniciais do ensino fundamental: uma revisão de literatura. Ensino Em-Revista, Uberlândia, v. 17, n. 1, p. 539-560, jul./dez. 2010. Disponível em: http://www.seer.ufu.br/index.php/emrevista/ article/view/ 8189/5205. Acesso em 07 jun. 2019.

MONTEIRO, M. A. A.; TEIXEIRA, O. P. B. O ensino de física nas séries iniciais do ensino fundamental: um estudo das influências das experiências docentes em sua prática em sala de aula. Investigações em Ensino de Ciências, Porto Alegre, v. 9, n. 1, p.7-25, 2004. Disponível em: http://www.if.ufrgs.br/ienci/ artigos/Artigo_ID108/v9_n1_a2004.pdf. Acesso em: 16 out. 2019.

MUJOL, S. G. M; LORENZETTI, L. A Abordagem Ciência, Tecnologia E Sociedade nos Anos Iniciais do Ensino Fundamental. V Simpósio Nacional de Ensino de Ciência e Tecnologia. Ponta Grossa - PR, 24 a 26 de nov. de 2016.

MUNAKATA, K. O livro didático: alguns temas de pesquisa. Revista Brasileira de História da Educação, v. 12, n.3, p.179-197, set./dez. 2012. Disponível em: 295 http://www.periodicos.uem. br/ojs/index.php/rbhe/article/view/38817.Acesso em: 23 ago. 2018.

NASCIMENTO, G. G. O. O livro de biologia no ensino de biologia. 2002. Dissertação (Mestrado em Educação) - Universidade de Brasília, Brasília, 2002.

PASCHINI NETO, M. Movimento Ciência-Tecnologia-Sociedade (CTS) nos textos sobre astronomia em livros didáticos de ciências do ensino fundamental. 2011. Dissertação (Faculdade de Ciências Humanas Curso Pós-Graduação em Educação) - Universidade Metodista de Piracicaba, Piracicaba, 2011.

PAVÃO, A. C.; FREITAS, D. (org.). Quanta ciência há no ensino de ciências. São Carlos: EdUFSCar, 2008.

PINHÃO, F.; MARTINS, I. Modos de agir de textos didáticos de ciências: discutindo o tema saúde e ambiente. Trabalho, educação e saúde, Rio de Janeiro, v.11, n.1, p.73-91, jan./abr. 2013. Disponível em: http://www.scielo.br/scielo.php?pid=S1981-77462013000100005\&script=sci_ abstract\&tlng=pt. Acesso em: 23 ago. 2019.

PINHEIRO, N. A. M.; SILVEIRA, R. M. C. F.; BAZZO, W. A. O contexto científico-tecnológico e social acerca de uma abordagem crítico-reflexiva: perspectiva e enfoque. Revista Iberoamericana de Educación, n. 49, p. 1-14, mar. 2009. Disponível em:< http://www.rieoei.org/2846.htm>. Acesso em: 15 jun. 2018.

PRAIA, J.; CACHAPUZ, A.; GIL-PÉREZ, D. A hipótese e a experiência científica em educação em ciência: contributos para uma reorientação epistemológica. Ciência \& Educação, Bauru, v. 8, n. 2, p. 253-262, 2002. Disponível em: http://www.scielo.br/scielo.php?script=sci_ arttext\&pid=S1516-73132002000200009. Acesso em: 23 ago. 2019.

REIS, P. Da discussão à ação sociopolítica sobre controvérsias sócio-científicas: uma questão de cidadania. Ensino de Ciências e tecnologia em Revista, v. 3, n. 1, p.1-10, jan/jun. 2013. Disponível em: http://repositorio.ul.pt/bitstream/10451/9577/3/DA\%20DISCUSS\%C3\%83O\%20 \%C3\%80\%20A \%C3\%87\%C3\%83O.pdf>. Acesso em: 15 mar. 2017.

ROSA, S. E.; AULER, D. Não neutralidade da ciência-tecnologia: problematizando silenciamentos em práticas educativas CTS. Alexandria: Revista de Educação em Ciência e Tecnologia, v. 9, n. 2, p. 203-231, nov. 2016. Disponível em: <https://periodicos.ufsc.br/index.php/alexandria/article/ view/1982-5153.2016v9n2p203. Acesso em: 14 mar.2019. 
RUPPENTHAL, R.; SCHETINGER, M. R. C. O sistema respiratório nos livros didáticos de ciências das séries iniciais: uma análise do conteúdo, das imagens e atividades. Ciência $\boldsymbol{\&}$ Educação, v. 19, n.3, p.617-632, 2013. Disponível em: https://www.redalyc.org/html/2510/251028539012/. Acesso em: Acesso em: 14 jun. 2015.

SACRISTÁN, J. G. O Currículo: uma reflexão sobre a prática. $3^{a}$ ed. Porto Alegre: Artmed, 2000.

SALLA, H. M. Estudos CTS e transgenia: análise de materiais didáticos do ensino médio. 2016. 219 f. Dissertação (Mestrado em Educação para Ciência) - Universidade Estadual Paulista, Bauru, 2016.

SANTOS, R. A. dos. A não neutralidade na perspectiva educacional Ciência-TecnologiaSociedade. 2012. 100 f. Dissertação (Mestrado em Educação), Centro de Educação, Universidade Federal de Santa Maria, Santa Maria, 2012.

SANTOS, R. A. dos; AULER, D. Ampliação da concepção de participação no campo CTS. In: X ENPEC - Encontro Nacional de Pesquisa em Educação em Ciências, 2015, Águas de Lindóia, SP. Anais do Encontro Nacional de Pesquisa em Educação em Ciências. Águas de Lindóia: ABRAPEC, 2015.

SANTOS, R. A. dos. Busca de uma participação social para além da avaliação de impactos da Ciência-Tecnologia na Sociedade: sinalizações de práticas educativas CTS. 203 p. Tese (Doutorado em Educação) - Universidade Federal de Santa Maria, Santa Maria, 2016.

SANTOS, W. L. P. Contextualização no ensino de ciências por meio de temas cts em uma perspectiva crítica. Ciência \& Ensino, v.1, número especial, p. 1-12, nov. 2007a. Disponível em: http://files. gpecea-usp.webnode.com.br/200000358-0e00c0e7d9/AULA\%206-\%20TEXTO\%2014-\%20 CONTEXTUALIZACAO $\% 20$ NO $\% 20$ ENSINO $\% 20$ DE $\% 20$ CIENCIAS $\% 20$ POR $\% 20$ MEI.pdf Acesso em: 15 mar. 2015.

SANTOS, W. L. P. Educação científica na perspectiva de letramento como prática social: funções, princípios e desafios. Revista Brasileira de Educação, São Paulo, v. 12, n.36, set/dez. 2007. Disponível em: http://www.scielo.br/pdf/rbedu/v12n36/a07v1236.pdf. Acesso em: 10 jun. 2017.

SANTOS, W. L. P. Educação científica humanística em perspectiva freireana: resgatando a função do ensino de CTS. Alexandria Revista de Educação em Ciência e Tecnologia. v. 1, n. 1, p. 109-131, mar. 2008. Disponível em: http://alexandria.paginas.ufsc.br/files/2012/03/WILDSON. pdf. Acesso em: 10 jun. 2018.

SANTOS, W. L. P. Educação CTS e cidadania: confluências e diferenças. Amazônia- Revista de Educação em Ciências e Matemáticas, v. 9, n. 17, p. 49-62, jul/dez. 2012. Disponível em: https:// periodicos.ufpa.br/index.php/revistaamazonia/article/view/1647/2077. Acesso em: 10 jun. 2019.

SANTOS, W. L. P.; SCHNETZLER, R. P. Educação em química: compromisso com a cidadania. $4^{a}$ ed. Ijuí: Editora da Unijuí, 2010.

SASSERON, L. H.; CARVALHO, A. M. P. de. Almejando a alfabetização científica no ensino fundamental: a proposição e a procura de indicadores do processo. Investigações em Ensino de Ciências, v.13, n.3, p.333-352, 2008. Disponível em: http://www.if.ufrgs.br/ienci/artigos/Artigo_ ID199/v13_n3_a2008.pdf. Acesso em: 25 mar. 2016.

SÁ-SILVA; J. R.; ALMEIDA, C. D. de. GUINDANI, J. F. Pesquisa documental: pistas teóricas e metodológicas. Revista Brasileira de História \& Ciências Sociais, v. 1, n.1, p. 1-15, jul. 2009. Disponível em: https://periodicos.furg.br/rbhcs/article/view/10351/pdf. Acesso em: 12 jan. 2019. 
STRIEDER, R. B. Abordagens CTS na educação científica no Brasil: sentidos e perspectivas. Tese de doutorado. 2012. 283 f. Tese de doutorado (Programa de Pós-Graduação Interunidades em Ensino de Ciências) - Universidade de São Paulo, São Paulo, 2012.

STRIEDER, R. B.; KAWAMURA, M. R. D. Perspectivas de participação social no âmbito da educação CTS. Uni-pluri/versidad, v. 14, n. 2, p.101-110, 2014. Disponível em: http://aprendeenlinea.udea. edu.co/revistas/index.php/unip/article/viewArticle/20061. Acesso em: 22 set. 2017.

\section{NOTAS}

1 O PNLD é um programa de aquisição e distribuição de livros e materiais didáticos, que tem grande relevância no âmbito da política educacional brasileira. Interfere diretamente na oferta dos livros, indicando critérios avaliativos e selecionando coleções que são recomendadas para a escolha dos professores que, posteriormente, são adquiridas com recursos públicos e distribuídas em todas as escolas atendidas (MUNAKATA, 2012).

Submetido em 09/11/2019

Aprovado em 25/04/2020

\section{Contato:}

Instituto Federal de Educação, Ciência e Tecnologia do Paraná - Campus Irati

R. Pedro Koppe, n. 100 - Vila São João

CEP 84.507-302 - Irati, PR - Brasil 